\title{
AN EXPERIMENT IN THE USE OF DRILL INSTRUCTORS IN LANGUAGE LABORATORIES
}

\author{
James Ferrell \\ University of Michigan
}

The present paper is an attempt to describe and discuss a type of language laboratory at the University of Michigan which is implemented somewhat differently from the conventional one. It employs drill instructors, supervised pattern practice, and group repetition as well as the more customary adjunct of a tape recorder. The paper will begin with a brief account of general instruction methods in the language course and of the laboratory as it is utilized at present, and will conclude with some observations on improvements that seem to be indicated in the light of experience gained during the past six or seven months.

The course is one in first-year Russian. It meets four hours each week. It is built around Cornyn's Beginning Russian, a textbook modelled in general on the materials used in the Intensive Language Program of the American Council of Learned Societies, but with certain improvements in the concentration of material by grammatical categories. The textbook, like most manuals of its type, employs for its earlier lessons a phonemic transcription, contains large amounts of set conversational materials for memorization, and, although representing a considerable improvement over most of the socalled "army method" texts in that it contains some rather well-planned grammatical exercises, must nevertheless be supplemented with a large number of additional materials for pattern practice and kindred exercises for the utilization of vocabulary within the morphological and syntactic categories under study.

The creation of a special Russian language laboratory was partly intentional and partly accidental. The Slavic Department had long been eager to experiment with a form of laboratory period that would be somewhat more flexible than is possible during a compulsory half-hour attendance at the 
University's large central language laboratory. Overcrowding of this central facility made the college authorities agreeable to the setting up of a special first-year Russian laboratory that would utilize normal classroom space at times when it was not being tenanted by classes. It set aside a sum of money sufficient for the purchase of a good portable tape recorder and amplifier ${ }^{\mathfrak{l}}$ and for the payment of a language drillmaster $^{2}$ for two hours a day, four times a week.

The minimal purpose of the first half-year of the laboratory was that of teaching comprehensible Russian pronunciation, improving the student's passive understanding of spoken Russian, ensuring that each student should be able to reproduce from memory the assigned Russian text on hearing the English equivalent, or be able to give the (or a) correct response to a Russian question or command.

A native Russian member of our staff recorded the "sentences" and "review" sections of the textbook on tape with pauses for repetition. She also recorded some rather extensive exercises involving minimal pairs. ${ }^{3}$ The use of tapes and a single recorder under the care of the drill-master has proved to be considerably cheaper and better than the use of records in the central laboratory. Since the tape recorder and tape were handled only by the drill-masters who have had instruction in its care, breakage and other forms of damage were reduced to a minimum. In addition a single tape suffices for the whole first-year group. Because the equipment and materials are of good quality and because tape is not subject to the same deterioration from scratches and wear as discs are, the reproduction is excellent. 4

During the playing of the tapes, the drill-master moves among the students listening to their repetitions. He takes notes on any particular inadequacies that each student may be showing. Where these inadequacies tend to be general in type,

1. Ampex \#601 Recorder and \#620 Amplifier.

2. The pay and the actual total time involved are roughly one-third of that of a teaching fellow.

3. Despite the present feeling of disillusionment that some of the more advanced applied linguists appear to feel about minimal pairs because they are generally briefer than normal utterances, we have found their use, on the whole, beneficial in aiding the student to distinguish and reproduce phonemic distinctions in a foreign language.

4. It should be noted that we were fortunate in that most of the classrooms at Michigan are adequately treated to cut down on echo. 
he gives the class corrective drill in the problem; where the inadequacy is special, he speaks to the student privately. The tape and supplementary exercises normally take about one half of the thirty-minute period for the first three days of the four-day lesson. On the fourth day this fifteen minute period is used for checking memorization of the text. The remaining fifteen minutes of each day are devoted to pattern practice based on the "sentences" unless, as is not infrequent, there is other, more pressing business. This pattern practice is similar to, but somewhat simpler than the materials used in class. More complex materials require both smaller groups of students and greater experience in handling problems that are characteristic of the classroom proper.

As was noted above, more pressing matters not infrequently cut down on the amount of time devoted to pattern practice in the laboratory. Examples of such matters are the need for maximal practice in spelling during the change-over from a phonemic to the Cyrillic alphabet. ${ }^{5}$ The shift in alphabet proves rather painful for the students, and a large amount of time and energy has to be spent in helping them during this period. At times mass forgetting on the part of the students of past material that had once appeared to be fairly well mastered has led to the use of the laboratory for drill in these specific topics.

At this point it might be helpful to attempt to assess on the basis of the Department's experience so far the advantages and disadvantages of this type of laboratory as against the conventional one.

In respect to attendance the laboratory with a drill master offers a gratifying improvement. This is no doubt due in part to the keeping of attendance rolls by the drill master and weekly reports to the instructors on all absences, but it would also seem to be due to a sense of immediate benefit that the students receive from their laboratory period. Moreover, in this connection, we must not forget that language is, after all, a social phenomenon. It normally is learned and practiced among groups of people rather than alone. The sense of group

5. I think that all the instructors in first-year Russian feel that it would be advantageous to begin the first lesson in the Cyrillic orthography with the phonemic transcript subordinated to a secondary position. 
participation and group accomplishment may also play a part in the improvement in attendance.

The pronunciation of this year's class shows a general advance over that of past years. The students profit, as one might expect, from direct corrections of pronunciation faults while learning the taped sentences. They also profit from the brief conferences where attempts are made to indicate the position of the speech organs.

The laboratory has made an important contribution in relieving the classroom period of a number of its more burdensome chores. The time saved from checking on memorization and spot reviewing of forgotten materials gives the classroom instructor more time for classroom exercises in the items of linguistic structure on which he is concentrating. Finally, practice in the laboratory on pattern materials similar to, but not identical with, those used in the classroom serves to give meaningful reinforcement to the learning process.

The laboratory has the advantage of serving as a training ground for potential instructors. It gives the drill master an opportunity to learn the techniques of teaching without being confronted with all the difficulties at one time. It provides him whatever advantages that may be gained from conferences and discussion with the regular instructors on topics related to the conduct and future planning of the laboratory and the associated classes. Finally, in this connection, it gives the department a chance to observe the talent and effectiveness of the drill masters.

There is common benefit for the teacher and the drill master (and ultimately for the students) in continuing discussions of the students, their progress, and their failings, that must be carried on from week to week. Likewise, the discussion of the course materials results in improved planning. The opinions and observations of two people does lead to more objective assessments than would result from those of one. Furthermore the division of labor results in neither the teacher's nor the drill master's being confronted with the need of correcting the less talented students on all fronts simultaneously.

In respect to cost the laboratory with drill masters probably is no more expensive than the conventional laboratory when the cost of space, breakgage and of wear of machines and records is taken into account.

The foregoing appear to be the chief advantages of a language laboratory under a drill master. However, it should be 
pointed out that the conventional laboratory does havecertain features of superiority of its own. The conventional laboratory, for instance, allows the student to make replays of materials as often as he may wish in order to gain practice on specific points of difficulty. Moreover the conventional laboratory lends itself rather better for use of certain types of exercises, particularly exercises consisting of passive listening followed by questions to be answered in writing: e.g., brief anecdotes followed by exercises based on questions concerning the content.

However, there is certainly nothing that per se excludes the instructor's utilizing the conventional laboratory for such purposes in addition to his utilizing the laboratory with drill masters for those functions which it performs better. In just such an articulation of the two types of laboratories would appear to be one of the major areas in which our use of the laboratory could be improved. That such additional use of the conventional laboratory would increase the total time spent by the student in laboratory work to something approaching four hours a week could be taken into account in decreasing other assignments. More extensive use of laboratory facilities at the cost of unsupervised home'study would not represent a loss since the average student in a first-year language course tends to be very wasteful of time in studying alone. 